\title{
ENSINO DE CONCORDÂNCIA VERBAL DE TERCEIRA PESSOA DO PLURAL POR MEIO DE SUPORTES DIGITAIS NO ENSINO FUNDAMENTAL
}

\section{TEACHING OF THIRD-PERSON PLURAL SUBJECT-VERB AGREEMENT WITH DIGITAL MEDIA IN MIDDLE SCHOOL}

\section{Gilson Costa Freire ${ }^{1}$}

\author{
Xella Ohana da Cunha Nascimento ${ }^{2}$
}

Resumo: Este artigo descreve uma mediação pedagógica aplicada numa turma de $7^{\circ}$ ano do Ensino Fundamental para o trabalho com a concordância verbal de $3^{\text {a }}$ pessoa do plural, por meio de atividades de produção de textos de diferentes gêneros, distribuídos num contínuo oralidadeletramento (BORTONI-RICARDO, 2004), em suportes digitais. O objetivo foi propiciar o multiletramento dos alunos seja no uso de novas tecnologias aplicadas ao ensino, seja na ampliação de seu repertório linguístico quanto à concordância verbal segundo as normas urbanas de prestígio. Os resultados mostraram um crescimento na aplicação da regra em direção à semicategorização (LABOV, 2003) no decorrer das atividades.

Palavras-chave: Concordância verbal; Variação; Novas tecnologias; Letramento

\begin{abstract}
This article describes a pedagogical mediation applied in a 7th grade middle school class to work with third-person plural subject-verb agreement, through activities of producing texts of different genres, distributed in a continuous orality-literacy (BORTONI-RICARDO, 2004), with digital media. The objective was to promote the multiliteracy of students in the use of new technologies applied to teaching and in the expansion of their linguistic repertoire concerning verbal agreement according to prestige urban norms. The results showed a growth in the application of the rule toward semicategorization (LABOV, 2003) during the activities.
\end{abstract}

Keywords: Verbal agreement; Variation; New technologies; Literacy

\section{Introdução}

Este trabalho constitui o produto de uma pesquisa-ação desenvolvida no curso de mestrado profissional em Letras (ProfLetras) na qual se aplicou uma mediação pedagógica

\footnotetext{
${ }^{1}$ Doutor em Letras Vernáculas (Língua Portuguesa) pela Universidade Federal do Rio de Janeiro (UFRJ). Professor Adjunto no Departamento de Letras e Comunicação da Universidade Federal Rural do Rio de Janeiro (UFRRJ). Desenvolve pesquisas sobre variação e mudança sintática relacionadas ao sistema pronominal brasileiro frente ao português europeu. Atua no ProfLetras da UFRRJ, orientando pesquisas sob a perspectiva das contribuiçõos dos estudos variacionistas. E-mail: gilsoncfreire@ yahoo.com.br

${ }^{2}$ E-mail: Professora da Educação Básica em São João do Meriti (TJ). E-mail: xellacunha@gmail.com
} 
sobre a concordância verbal de terceira pessoa do plural em uma turma do $7^{\circ}$ ano do Ensino Fundamental (doravante EF) a partir de produções textuais dos próprios alunos organizadas em um contínuo oralidade-letramento, nos termos de Bortoni-Ricardo (2004).

No que diz respeito ao fenômeno variável focalizado na pesquisa, não é incomum a ocorrência, em textos produzidos por estudantes, de sentenças cuja concordância verbo-sujeito muitas vezes diverge da variedade culta, tanto em contextos de sujeitos pré-verbais, como de sujeitos pós-verbais, como ilustram os exemplos abaixo extraídos de textos produzidos pelos alunos por ocasião da mediação pedagógica aplicada nesta pesquisa:

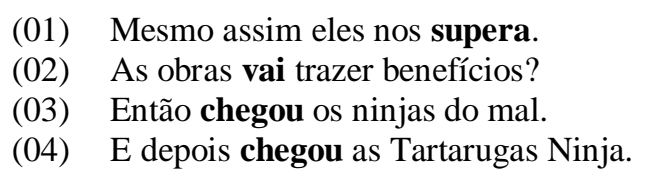

Embora todas as sentenças acima não apresentem a aplicação da regra de concordância verbal prescrita pela gramática normativa, há uma diferença na avaliação delas pela sociedade letrada: as duas primeiras (com sujeito pré-verbal) são muito mais estigmatizadas do que as duas últimas (com sujeito pós-verbal), já que estas podem aparecer na fala espontânea de indivíduos cultos em situações não monitoradas. De acordo com pesquisas na área da Sociolinguística Variacionista (cf. GRACIOSA, 1991; SCHERRE; NARO, 1997; MONGUILHOT, 2001; OLIVEIRA, 2005), a concordância verbal de terceira pessoa do plural no Português do Brasil é uma regra variável, que sofre influência de condicionamentos linguísticos e extralinguísticos.

Não obstante essa variação, sabemos que, dentre os tópicos do ensino de Língua Portuguesa, a concordância verbal ocupa tradicionalmente lugar de destaque, haja vista as frequentes marcações que os professores fazem nos textos dos alunos a título de correção, quando há nesse campo desvios em relação às prescrições da gramática tradicional. Dessa forma, a escolha do tema justifica-se na medida em que percebemos que, ao longo do EF, há muitos alunos que manifestam em sua escrita embaraço na aplicação da regra de concordância verbal de terceira pessoa do plural, prestigiada pelas variedades urbanas cultas.

Por outro lado, percebemos quanto as novas tecnologias da informação e comunicação (NTIC) estão inseridas e disseminadas pela sociedade. No contexto social e econômico em que vivemos, as novas mídias são usadas a todo momento no nosso cotidiano e por boa parte dos alunos, sobretudo os das regiões metropolitanas do país, nas quais há um maior acesso a essas novas tecnologias. Nesse contexto, a escola não pode ignorar a presença e a utilidade que essas mídias possuem, em especial a internet, como parte das práticas sociais vivenciadas pelos 
discentes em seu cotidiano e como um universo que possibilita eventos de letramento digital. Sabendo que a linguagem não é somente um instrumento de comunicação, mas uma forma de interação, as práticas sociais de letramento articuladas às NTIC seriam muito mais proveitosas e significativas se utilizadas nas aulas de Língua Portuguesa.

Pensando no potencial das NTIC a serviço do ensino (cf. RIBEIRO, 2012, 2016), a mediação pedagógica aplicada propôs um trabalho de produção de textos com foco na concordância verbal de terceira pessoa do plural a partir do emprego de diferentes suportes digitais - aplicativo de troca de mensagens instantâneas (WhatsApp), rede social (Facebook) e blog - por uma turma do $7^{\circ}$ ano do EF, de modo a evidenciar para os alunos o papel social dos textos produzidos, já que estes foram destinados efetivamente a um público leitor, que não unicamente o professor.

Por conseguinte, a pesquisa-ação desenvolvida promoveu a abordagem do tema concordância verbal a partir do emprego de suportes digitais como ferramenta pedagógica, tendo como objetivos (a) possibilitar aos alunos o multiletramento a partir do manejo de novas tecnologias; (b) fazer com que esses mesmos alunos ampliassem seu repertório linguístico no que diz respeito à concordância verbal de terceira pessoa do plural em textos distribuídos ao longo de um contínuo de oralidade-letramento (BORTONI-RICARDO, 2004).

Este artigo apresenta a seguinte estrutura: na primeira seção, apresentamos o aporte teórico que orientou a pesquisa; na segunda, explicitamos a metodologia utilizada para alcançar os objetivos propostos; na terceira seção, fazemos a descrição da proposta de intervenção pedagógica aplicada e comentamos os resultados. Por fim, fazemos apontamentos nas considerações finais a respeito dos objetivos alcançados pela pesquisa.

\section{Pressupostos teóricos: Sociolinguística Variacionista e ensino}

Como a pesquisa se propôs a tratar de um fenômeno linguístico variável, passamos a expor a relação entre a Teoria da Variação ou Sociolinguística Variacionista e o ensino (cf. VIEIRA; FREIRE, 2014), que serviu de aporte teórico para a mediação pedagógica aplicada, destacando a teoria dos contínuos de variação linguística propostos por Bortoni-Ricardo (2004).

A Sociolinguística Variacionista postula não só que a variação é uma propriedade regular a qualquer sistema linguístico, mas também que a regra variável é uma regra de produção, afetada por restrições variáveis em função da quantidade de casos em que essa mesma regra se aplica referente ao total de ocorrências do contexto em pesquisa. Assim, é de suma importância que sejam observados as condições e o contexto em que se realiza 
determinada variação, pois existe influência contínua e dosada de fatores estruturais e sociais sobre o fenômeno variável, o qual pode representar uma mudança em progresso ou constituir uma variação estável. É necessária, pois, a verificação dos fatores que favorecem ou inibem a aplicação de uma regra, sendo esses fatores linguísticos ou sociais, através de um estudo quantitativo dos dados obtidos.

Segundo Labov (2003), os fenômenos linguísticos podem manifestar três tipos de regras: a categórica, a semicategórica e a variável. A categórica diz respeito à aplicação de um único tipo de uso na língua, referente a $100 \%$ dos casos; já a semicategórica é marcada pela oscilação de duas formas alternantes, em que uma delas é empregada em 95\% a 99\% das ocorrências, podendo-se considerar esta a única forma utilizada na língua, apesar de as outras formas serem identificadas e passíveis de uso em estruturas e contextos específicos pelos falantes; por fim, a terceira regra, a variável, é caracterizada pela produtividade na utilização das formas alternantes, entre 5\% a 95\% das estruturas analisadas, a partir de fatores linguísticos e extralinguísticos.

Diferentes estudos sociolinguísticos sobre a variedade brasileira do Português (cf. GRACIOSA, 1991; SCHERRE; NARO, 1997; MONGUILHOTT, 2001; OLIVEIRA, 2005) constataram que a concordância verbal está relacionada tanto a fatores estruturais quanto a sociais, com destaque para esses últimos, visto que há uma polarização no que diz respeito à aplicação da regra: de um lado, estão os indivíduos escolarizados entre os quais ela é semicategórica; de outro, os indivíduos com baixa ou nenhuma escolaridade cuja fala manifesta regra variável.

Tendo em vista a concordância de terceira pessoa do plural, interessam à Sociolinguística Laboviana os padrões normais ou corriqueiros de uso da língua. Esses comportamentos linguísticos são descritos e quantitativamente testados, podendo-se identificar a partir daí as formas de uso comum e aquelas que recebem preferência no contexto social. A chamada norma culta está relacionada à prática linguística do "grupo social escolarizado e que domina a fala e a escrita típica de meios letrados" (VIEIRA; FREIRE, 2014, p. 82), sendo essa norma o objeto de ensino da escola.

No entanto, essa norma culta não é uniforme, mas plural e não corresponde exatamente à que está codificada nas gramáticas tradicionais (cf. FARACO, 2008). Assim, para um efetivo ensino de Língua Portuguesa na escola, deve-se garantir ao aluno "o domínio das normas urbanas de prestígio, especialmente em sua modalidade escrita, mas também nas situações orais 
públicas em que seu uso é socialmente requerido" (PNLD, 2010, p. 20), de maneira que se faz necessário o reconhecimento das

estruturas que pertencem às normas/variedades cultas, na língua oral e na escrita brasileiras, de modo a permitir que se avalie a proximidade ou a distância dessas normas em relação (i) a outras normas já dominadas pelos estudantes quando chegam à escola (as normas vernaculares), e (ii) a outras normas que se apresentam nos diversos gêneros textuais trabalhados nas aulas de Português, que lidam com materiais da sincronia atual e até de outras sincronias" (VIEIRA; FREIRE, 2014, p. 84).

Entre as contribuições dos estudos sociolinguísticos ao ensino, está a teoria dos contínuos de variação proposta por Bortoni-Ricardo (2004). Para compreender o fenômeno da variação linguística no português brasileiro, a autora propõe três linhas imaginárias ou contínuos que são os seguintes: contínuo de urbanização, contínuo de oralidade-letramento e contínuo de monitoração estilística.

O contínuo de urbanização constitui uma linha imaginária com dois polos: em uma das pontas encontram-se as variedades rurais usadas por comunidades isoladas pela dificuldade geográfica de acesso, onde há o predomínio da cultura de oralidade; na outra ponta ficam as variedades urbanas, que tiveram maior influência dos processos de padronização da língua e de culturas de letramento. No espaço entre as pontas, está a zona rurbana, constituída tanto por migrantes oriundos da zona rural, que mantiveram seus antecedentes culturais em seu repertório linguístico, quanto por comunidades localizadas em ambientes semirrurais, que recebem influência urbana pela mídia e por outras tecnologias. Sendo assim, "podemos situar qualquer falante do português brasileiro em um determinado ponto desse contínuo, levando em conta a região onde ele nasceu e vive" (BORTONI-RICARDO, 2004, p. 52).

Já o contínuo de oralidade-letramento é a linha imaginária que polariza os eventos de comunicação como mediados pela escrita ou pela língua oral. Se um evento tiver por base a língua escrita, é denominado evento de letramento, ou seja, estará sujeito à ação de agências padronizadoras, como a escola e a imprensa, manifestando maior compromisso com a tradição gramatical defendida por essas agências. No outro polo desse contínuo, estão os eventos de oralidade, caracterizados pela espontaneidade, em que não há interferência direta da língua escrita com toda a carga imposta pela tradição escolar. No entanto, há eventos de comunicação que se situam na linha intermediária desse contínuo, representados por textos que apresentam pontos de contato com as regras da escrita, mas sem perder traços de espontaneidade típicos da modalidade oral.

Por fim, o contínuo de monitoração estilística é construído por tipos de interação, mostrando em suas extremidades estilos não monitorados (informais), realizados de forma 
espontânea, com ínfima atenção à forma da língua, e estilos monitorados (formais), que demandam atenção e planejamento por parte do falante. Bortoni-Ricardo (2004) enumera os fatores que nos suscitam a monitoração de estilo: o ambiente, o interlocutor e o tópico da conversa.

\section{Metodologia}

A pesquisa foi desenvolvida com uma turma de $7^{\circ}$ ano do EF, com 14 meninas e 19 meninos, entre 12 e 16 anos, da Escola Municipal Maria Clara Machado, localizada em Duque de Caxias - RJ. Tratou-se de uma pesquisa-ação, uma vez que representou um conjunto sistemático de ações para resolução de um problema coletivo no qual a pesquisadora e os participantes da situação-problema (o manejo da concordância verbal de terceira pessoa do plural em diferentes contextos estruturais) estavam envolvidos, de modo cooperativo ou participativo (cf. THIOLLENT, 2011). Assim, buscou-se promover um tratamento didático da concordância verbal de terceira pessoa do plural a partir de textos produzidos pelos alunos, adotando como orientação metodológica o contínuo oralidade-letramento proposto por BortoniRicardo (2004) para organização dos gêneros. O contínuo rural-urbano não teria como ser aplicado, pois os alunos envolvidos pertenciam a uma comunidade situada em área urbana, qual seja, o município de Duque de Caxias, integrante da região metropolitana do Rio de Janeiro. Quanto ao contínuo de monitoramento, só seria possível aplicá-lo se os informantes (no caso os alunos) fossem indivíduos completamente letrados: ora, um indivíduo em cujo repertório linguístico não há formas prestigiosas não vai exibir diferenças significativas de uso da língua em situações formais, já que isso depende de seu processo de letramento (cf. DUARTE; SERRA, 2015). Por conseguinte, optamos pelo contínuo de oralidade-letramento, especialmente pelo fato de o processo de letramento poder ser trabalhado na escola por meio da análise do comportamento linguístico dos alunos nos diferentes gêneros apresentados na abordagem da concordância verbal: desde os mais comprometidos com a tradição gramatical (textos representativos de eventos de letramento), até os menos comprometidos com essa mesma tradição (textos representativos de eventos de oralidade).

Dessa forma, foi elaborada e aplicada uma mediação pedagógica com atividades de produção textual que envolveram gêneros representativos dos diferentes pontos do contínuo adotado, observando tanto a aplicação quanto a não aplicação da regra de concordância, de modo que os alunos percebessem os contextos variáveis ao longo do contínuo, rompendo assim com um ensino meramente prescritivo.

A mediação pedagógica compreendeu oito etapas, cujo detalhamento será apresentado 
na próxima seção. Para o tratamento da concordância verbal de terceira pessoa do plural, as atividades propostas à turma partiram de textos distribuídos ao longo do contínuo de oralidadeletramento, iniciando por aqueles mais ligados à oralidade, como conversas por troca de mensagens no aplicativo WhatsApp, passando por comentários opinativos postados no Facebook, chegando até aos mais representativos da cultura de letramento, como resumos, que foram publicados em um blog, a fim de verificar o comportamento da escrita dos alunos quanto ao fenômeno linguístico focalizado.

\section{A mediação pedagógica}

Nesta seção descreveremos as etapas da mediação pedagógica como proposta de intervenção em uma turma de $7^{\circ}$ ano do EF, apresentando o diagnóstico encontrado, as atividades desenvolvidas durante a pesquisa e a análise dos resultados obtidos nas produções textuais relacionados à aplicação da regra concordância verbal de terceira pessoa do plural.

\subsection{Etapa 1: Apresentação do projeto e produção inicial}

A primeira etapa foi iniciada com a apresentação do projeto da mediação pedagógica, por meio da exibição de slides, sob o título "Produção de textos em mídias digitais", em que foi explicado à turma que, no decorrer do projeto, os alunos iriam produzir textos próprios nos suportes digitais WhatsApp, Facebook e blog.

No momento de exemplificar os textos a serem trabalhados, chamou-se a atenção dos alunos para observarem a variação do grau de espontaneidade e de obediência às determinações das gramáticas normativas que os textos apresentassem. As mensagens instantâneas trocadas com o aplicativo do primeiro suporte digital, por exemplo, apesar de serem um texto escrito, seu conteúdo e registro se aproximam muito de nossa forma de falar, assemelhando-se a uma conversa feita de forma oral. Já em reportagens e resumos encontrados nos blogs, o tipo de registro da escrita costuma ser mais comprometido com as orientações das gramáticas, por serem textos de circulação típicos da imprensa, considerada uma instância social padronizadora (cf. BORTONI-RICARDO, 2004).

Após essa apresentação, foi proposta a produção inicial: uma conversa (silenciosa) entre os alunos por meio da troca de mensagens escritas, fazendo uso do aplicativo WhatsApp. O tema orientado para a conversa foi "Os turistas que participarão das Olimpíadas". Foi comentada com os alunos a situação da cidade do Rio de Janeiro quanto à infraestrutura, à segurança, à saúde, aos locais para visitação, às instalações para receber turistas e atletas, 
citando em especial o caso da delegação da Austrália ao conhecer os seus aposentos na Vila Olímpica, que estavam em condições precárias.

Como preparo para essa atividade acontecer, foi conversado com os alunos, em aulas anteriores, acerca do uso consciente dos aparelhos celulares como ferramenta pedagógica nas aulas, além de ser realizada a leitura e a discussão da resolução do município que trata da proibição do uso desses aparelhos em sala de aula, salvo em atividade voltada para o ensino. Apesar de ter havido um trabalho prévio de conscientização com o aviso de que usaríamos o aplicativo WhatsApp numa das aulas, alguns alunos não trouxeram os celulares por não terem a autorização de seus responsáveis; outros por terem esquecido os aparelhos em casa; outros ainda por não os possuírem. Por consequência, na aula da primeira etapa do projeto, havia 30 alunos e apenas 10 aparelhos disponíveis. Sendo assim, para que todos pudessem participar da atividade, os estudantes foram divididos em trios, cada grupo tendo como seu representante o "dono" do celular, de modo que um trio conversava com outro por meio do aplicativo. Para que essa atividade tivesse como ser realizada, a professora-pesquisadora disponibilizou aos alunos sua rede particular 3G, já que a escola não podia repassar a senha do Wi-fi para os alunos.

Decorridos 30 minutos, a conversa foi encerrada, tendo os grupos recebido uma folha de almaço, para que transcrevessem toda a conversa. Ao fim da aula, as folhas foram entregues à professora-pesquisadora. A turma foi bem receptiva à atividade diagnóstica, apesar dos contratempos referidos, tendo sido obtidas cinco conversas no total.

Considerando as conversas com trocas de mensagens pelo WhatsApp, representativas do polo de [+ oralidade] do contínuo, foram encontrados 62 dados relacionados à terceira pessoa do plural, cuja aplicação da regra de concordância verbal $(\mathrm{CV})$ pode ser observada na tabela a seguir:

Tabela 1: Índice de aplicação da regra de CV de $3^{\mathrm{a}}$ pessoa do plural em conversas via WhatsApp

\begin{tabular}{|c|c|c|}
\hline CONCORDÂNCIA & NÃO CONCORDÂNCIA & TOTAL \\
\hline 47 & 15 & 62 \\
\hline $76 \%$ & $24 \%$ & $100 \%$ \\
\hline
\end{tabular}

Fonte: Elaboração da autora-pesquisadora, Seropédica, 2016.

Como podemos ver na tabela, a atividade diagnóstica mostrou que os textos produzidos que se situavam no polo de [+ oralidade] manifestaram, em sua maioria, a aplicação da regra de concordância verbal de terceira pessoal do plural. Essa constatação reforça o que já fora observado por outros pesquisadores, como Graciosa (1991), segundo os quais, falantes de áreas 
urbanas tendem mesmo a preservar a concordância verbal, de modo que o índice de $76 \%$ de aplicação da regra não causou surpresa, principalmente em se tratando de alunos de região metropolitana.

No entanto, em aproximadamente $1 / 4$ das ocorrências, foram registradas formas de não concordância, conforme ilustram os exemplos a seguir:

(05) (...) alguns deles fala diferente (...)

(06) (...) os turistas não pode rever a mesma coisa.

Esse índice chama atenção pois, ainda que os alunos pertençam a uma área urbana com muito acesso à grande mídia e outras agências padronizadoras — houve um número considerável de não aplicação da regra em uma produção realizada em ambiente escolar. Isso certamente se explicaria pelo fato de a produção textual constituir um evento de comunicação marcado pela oralidade, em que não há tanta preocupação com as regras ditadas pela tradição gramatical.

Por outro lado, todos os dados obtidos nesta primeira etapa constituíram contextos com sujeito pré-verbal, que é a ordem mais frequente no Português Brasileiro, de modo que os casos de não aplicação da regra revelaram que os alunos precisavam aprimorar o letramento em estruturas de concordância verbal de terceira pessoa do plural não apenas em contexto de posição pós-verbal do sujeito (como era de esperar e acabou não aparecendo nesta etapa), mas também em contexto de sujeito pré-verbal, no qual a não aplicação da regra é estigmatizada por grupos sociais letrados, haja vista o fato de um indivíduo culto dificilmente deixar de manifestar a concordância de terceira pessoa do plural nesse último contexto, especialmente na escrita.

\subsection{Etapa 2: Apresentação do conceito de "concordância verbal" no contexto do}

\section{projeto}

A segunda etapa da mediação pedagógica foi iniciada com a apresentação de slides sobre o fenômeno linguístico focalizado: a concordância verbal.

Primeiramente, foram relembradas aos alunos quais seriam as plataformas digitais utilizadas no projeto "Produção de textos em mídias digitais": WhatsApp, Facebook e blog. Em seguida, foi esclarecido que, em todos os textos produzidos, além da coerência, coesão, pontuação e ortografia, os alunos deveriam estar atentos a um fenômeno da língua chamado "concordância verbal", que de forma simples foi apresentado como a combinação entre o verbo e o sujeito da oração. 
Foi conversado com os alunos que o fenômeno da concordância verbal apresenta variações na língua a depender do contexto estrutural (sujeitos pré e pós-verbais) e do grau de compromisso do gênero textual com as prescrições da gramática normativa. Porém foi evidenciado que, apesar de as variações serem próprias da língua, na escola há a oportunidade de conhecer e aprender a regra de concordância verbal típica das normas urbanas cultas, pois ela será exigida nos meios letrados da sociedade, de maneira que se espera que o cidadão a domine. Sendo assim, foi apresentado o slide que trazia a informação de que a combinação a ser seguida era de o verbo estar conjugado na mesma pessoa e no mesmo número expressos pelo sujeito da oração; em seguida, foram expostos exemplos desse tipo de combinação.

A partir daí foram colocadas algumas imagens da conversa que os alunos trocaram entre si através do aplicativo WhatsApp na etapa anterior, para que observassem se houve a aplicação da regra de concordância verbal ou não em cada trecho:

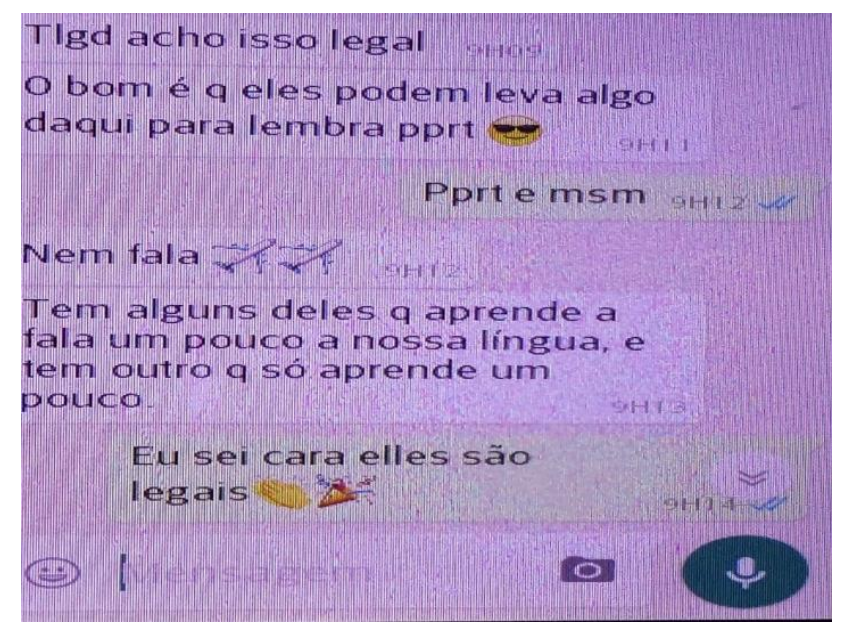

Figura 1. Conversa de WhatsApp (Fonte: Elaboração da autora-pesquisadora, Seropédica, 2016)

Os trechos de conversa expostos nos slides apresentaram tanto a aplicação, quanto a não aplicação da regra de concordância, conforme ilustram respectivamente os exemplos a seguir:

(07) (...) que eles podem levar algo (...)

(08) (...) alguns deles que aprende (...)

No momento da apresentação, foi comentada a questão de esses serem exemplos de textos mais voltados para a oralidade, e por isso a oscilação na aplicação da regra típica das variedades urbanas de prestígio: ora com concordância, ora sem concordância verbal.

Em seguida, foram mostrados trechos de textos representativos de eventos de letramento, o conto "A menina e as balas" de Georgina Martins e uma reportagem sobre a chegada de atletas à Vila Olímpica, em que foram destacadas as combinações padrão de concordância verbal. Os textos foram lidos parte a parte, destacando-se as ocorrências de 
concordância que são uma das marcas de textos próprios da cultura de letramento por seguir as normas das agências padronizadoras (cf. BORTONI-RICARDO, 2004).

Logo depois, foi entregue aos alunos uma folha de exercícios de fixação do assunto. Uma reação marcante desta etapa foi a feliz surpresa que os alunos demonstraram quando os seus próprios textos foram utilizados como exemplos do assunto que estava sendo tratado na aula, o que certamente para eles revestiu de sentido a produção inicial realizada na etapa anterior.

\subsection{Etapa 3: Módulo sobre o gênero comentário opinativo do Facebook e segunda} produção textual

A terceira etapa da sequência didática destinou-se à produção textual com o uso da plataforma digital Facebook. Assim que os alunos se acomodaram na sala de vídeo, foi explicado que nesta etapa do projeto eles usariam o Facebook. Em meio à animação demonstrada pela turma, foi esclarecido que os comentários não seriam aleatórios: deveriam ser sobre reportagens lidas e discutidas na sala.

Ainda sobre as Olimpíadas na cidade do Rio de Janeiro, foram selecionadas duas reportagens que tratavam de um mesmo assunto, porém com enfoques diferentes. Ambas discursavam sobre a campanha publicitária dos jogos paralímpicos da qual os atores Cleo Pires e Paulinho Vilhena participaram, tendo eles sido transformados em paratletas, fato que foi polemizado nas redes sociais. A primeira reportagem exibida era do jornal Folha de São Paulo $(\text { on-line })^{3}$ a qual trazia críticas verbalizadas por internautas acerca do assunto. A segunda reportagem foi retirada do site da revista $V_{o g u e}$, criadora dessa campanha publicitária, que relatava a homenagem positiva dos atores feita a dois paratletas renomados.

As reportagens foram lidas de forma coletiva, por terem sido exibidas na tela da televisão. Em seguida, pediu-se que os alunos refletissem sobre o assunto e expressassem sua opinião oralmente, respondendo às perguntas: "Os atores cometeram atos preconceituosos ou tiveram uma boa intenção? Por quê?".

Passado esse momento, a turma foi dividida em dois grupos que se revezariam na atividade de produção de comentários opinativos. Um grupo por vez se dirigiu à sala de informática para acessar a plataforma do Facebook, tendo cada componente solicitado a

\footnotetext{
${ }^{3}$ Disponível em <http://f5.folha.uol.com.br/celebridades/2016/08/campanha-transforma-cleo-pires-e-paulinhovilhena-em-paratletas-e-revolta-internautas.shtml>. Acesso em 28 de ago. 2016.

${ }^{4}$ Disponível em <https://vogue.globo.com/moda/moda-news/noticia/2016/08/somos-todos-paralimpicoscampanha-com-cleo-pires-e-paulinho-vilhena.html>. Acesso em: 28 de ago. 2016.
} 
"amizade" com a professora-pesquisadora para ter acesso às postagens das reportagens e inserir o seu comentário opinativo (atividades que foram previamente combinadas com a professora da sala de informática educativa, a qual direcionaria os alunos nesse momento, caso houvesse necessidades operacionais). Enquanto um grupo estava na sala de informática, o outro ficava na própria sala de aula com a professora-pesquisadora realizando uma atividade escrita sobre concordância verbal. Foram estipulados 25 minutos para a execução das atividades na sala de informática, de maneira a permitir o revezamento entre os grupos.

Levando em consideração que os comentários opinativos do Facebook estão na faixa intermediária do contínuo (+ oralidade; + letramento), foram contabilizadas 29 estruturas de terceira pessoa do plural, em cuja maioria se verificou a aplicação da regra de concordância verbal, como mostra a tabela adiante:

Tabela 2: Índice de aplicação da regra de CV de $3^{\mathrm{a}}$ pessoa do plural em comentários opinativos no Facebook

\begin{tabular}{|c|c|c|}
\hline CONCORDÂNCIA & NÃO CONCORDÂNCIA & TOTAL \\
\hline 28 & 01 & 29 \\
\hline $97 \%$ & $3 \%$ & $100 \%$ \\
\hline
\end{tabular}

Fonte: Elaboração da autora-pesquisadora, Seropédica, 2016.

Observamos, por meio da tabela, um avanço na aplicação da regra de concordância, em direção ao polo de [+ letramento]: a regra passa a ser semicategórica (cf. LABOV, 2003). Mais uma vez, não houve estruturas com sujeito posposto, registrando-se dados somente com orações na ordem direta. Curiosamente houve apenas uma única ocorrência de terceira pessoa do plural em que não se seguiu a regra de concordância:

(09) (...) mesmo assim eles nos supera.

Todavia o dado apresentado acima se deu com uma forma verbal de pouca saliência fônica, ou seja, com desinência de marcação do plural constituída apenas por - $m$ (supera/superam), marca típica de terceira pessoa do plural nos tempos verbais presente, pretérito imperfeito e futuro do pretérito do indicativo, a qual é sujeita à não concretização, de acordo com a descrição de trabalhos linguísticos que investigaram a atuação do fator saliência fônica na concordância de terceira pessoa do plural, como o de Scherre e Naro (1997).

Não obstante isso, o alto índice de aplicação da regra de concordância verbal encontrado nesta etapa constitui um fato interessante a ser analisado. Retomando a classificação proposta por Labov (2003), podemos dizer que a concordância, de regra variável na atividade diagnóstica, passou a ser semicategórica, o que pode ser efeito do processo pedagógico 
empreendido na etapa 2. Além disso, essa tendência mais forte à aplicação da regra poderia ser explicada pelo maior apuro manifestado pelos alunos da turma na realização da atividade então proposta, já que teria visibilidade para além dos muros da escola: a internet.

\subsection{Etapa 4: Módulo de atividades de fixação sobre concordância verbal}

A quarta etapa da mediação pedagógica ocorreu na sala de vídeo para utilização do notebook conectado à televisão para a exibição de slides. Houve uma conversa com os alunos sobre a variação de combinações do sujeito com o verbo nos eventos marcados pela oralidade, em que pode não haver a aplicação da regra de concordância. Como exemplos desse tipo de evento, foram trazidas novamente as mensagens das conversas no WhatsApp e o texto "Sketch - Dois homens tramando um assalto" de Luís Fernando Veríssimo, em que dois assaltantes demonstram dois tipos de diálogos: uma conversa entre si utilizando uma linguagem espontânea, sem formalidade, com gírias e estruturas verbais sem aplicação da regra de concordância verbal; e outro diálogo, agora com a chegada de um guarda, trazendo o tipo de linguagem e o assunto modificados com o objetivo de "disfarçar", de maneira que os personagens passam a usar termos formais, citar nomes de estudiosos e formar estruturas verbais segundo a regra de concordância, dando um ar de seriedade ao contexto, o que já aponta para características típicas dos eventos de letramento.

Ao exemplificar eventos intermediários, que estariam entre o polo de oralidade e o de letramento, foram exibidos alguns dos comentários opinativos referentes à atividade da etapa anterior: 


\begin{abstract}
Eles tiveram atitude boa de homenagia os paratletas, porem muitos pessoas nāo interpretaram bem o que eles quizeram mostra. Mais eles deveriam faz com os próprios paratletas

Curtir - Responder-21 de setembro às 21:37- Editado

eles ajudarao

Curtir Responder - 22 de setembro às 19:09

Bom sim tentaram ajudar a divulgar os jogos

Paraolímpicos mas fizeram do jeito errado por is so que deu muita revolta a todos os intemautas e de todos os públicos poderiam ser atletas reais dessa categoria mas năo tiveram que botar pessoas com satide em perfeito estado para divulgar a paraolimpiada só que de qual quer jeito funcionou assim todas pessoas prestaram atençăo pelo mesmo num momento como esse só que näo adianta olhar e dar o valor que eles tem somente agora por que eles tem que superar $1000 x$ o que agente supera todos os cias al eu te digo o que você passa todos os dias tarefas simples pode ser muito difícil e mesmo assim eles nos supera.

Curtir - Responder - 23 de setembro às 17:27

\section{Eles tiveram uma boa intençao}

\section{Curtir - Responder - 3 de outubro as 23:42}

Figura 2 - Comentário opinativo do Facebook (Fonte: Imagem captada da própria rede social da autorapesquisadora, Seropédica, 2016)

O texto acima apresentado pode ser considerado como intermediário, pois possui características tanto de um polo quanto de outro, apresentando ora a aplicação da regra (10), ora a não marcação da concordância (11):

(10) (...) muitas pessoas não interpretaram bem (...)

(11) (...) mesmo assim eles nos supera.

Como exemplos de textos de eventos marcados pelo letramento, os quais representam a escrita segundo as agências padronizadoras, como a imprensa, com suas prescrições e manuais, foram apresentadas duas reportagens, já que são textos bem representativos desse polo e utilizam de forma categórica a regra de concordância verbal.

Ao término desse momento com os slides, os alunos receberam folhas impressas com exercícios de fixação da regra de concordância verbal, com base nas sugestões de tópicos trazidas por Vieira (2014), a partir das reportagens exemplificadas nessa etapa.

\title{
3.5. Etapa 5: Módulo sobre o gênero resumo I
}

A quinta etapa foi realizada também na sala de vídeo da escola. Logo no início do encontro, foi conversado com a turma que, para participar da última produção textual referente ao suporte digital blog, os alunos deveriam produzir resumos para serem postados e, para isso, precisariam conhecer as características desse gênero. 
Ao começar o assunto, os discentes foram indagados sobre seus conhecimentos acerca do referido gênero textual. Alguns responderam de forma simples, porém sem conseguir detalhar o assunto. Em seguida, foram apresentados slides com as informações sobre o gênero em questão, que foram lidos e explicados. Como exemplificações foram usados resumos disponíveis em blogs: o primeiro foi referente ao filme "Lutero", o segundo, sobre o livro "O triste fim de Policarpo Quaresma"6 e o terceiro sobre o livro "Memórias Póstumas de Brás Cubas" ". Um trecho de cada resumo foi lido por alguns alunos, para que a turma tivesse conhecimento do tipo de linguagem usada nesse gênero textual, observando especialmente a concordância verbal.

Para fixar o reconhecimento do gênero focalizado na aula, foram apresentados gêneros textuais variados por meio de slides, para que os alunos contrastassem com os textos que se enquadravam na categoria resumo.

Após esse momento de atividades coletivas, cada aluno recebeu um resumo impresso sobre o filme "Desventuras em série", que deveria ser lido, observando as características do gênero. Em seguida, foram aplicadas perguntas sobre esse mesmo texto.

\subsection{Etapa 6: Módulo sobre o gênero resumo II: produção coletiva}

Como forma de treinamento, esta etapa propôs uma produção de resumo coletiva sobre uma narrativa. Ao se acomodarem na sala de aula, os alunos foram orientados a pegarem os cadernos, para que registrassem as características do gênero textual resumo tratadas na etapa anterior.

Em seguida, cada aluno recebeu uma folha impressa com a narrativa "A menina e as balas". Cada aluno deveria ler pelo menos três vezes o texto para compreendê-lo com clareza e marcar nele as ideias principais.

Após esse momento de leitura e mapeamento do texto, foi proposto que fosse feito um resumo coletivo dele, a partir do que se podia compreender.

Foi lembrado que o texto deveria ser escrito em prosa e conter, no primeiro parágrafo, pelo menos o título seguido de uma ideia genérica do conteúdo original. Assim, a professorapesquisadora, sendo a escriba, passou a registrar no quadro branco o resumo, que era formado

\footnotetext{
${ }^{5}$ Disponível em: <www.cfrbpensandoalto.blogspot.com.br/2010/08/resenha-sobre-o-filme-lutero〉. Acesso em: 12 de set. 2016.

${ }^{6}$ Disponível em: <www.juliescreveu.com.br/resumo-triste-fim-de-policarpo-quaresma-lima-barreto/>. Acesso em: 12 de set. 2016.

${ }^{7}$ Disponível em: <juliescreveu.com.br/resumo-memorias-postumas-de-bras-cubas-machado-de-assis/>. Acesso em: 12 de set. 2016.
} 
parte a parte com a turma, seguindo a sequência textual, conforme os alunos respondiam a partir das indagações realizadas. Por fim, cada aluno registrou no seu caderno o resumo feito coletivamente na sala de aula.

\subsection{Etapa 7: Produção de resumo de um filme}

A sétima etapa aconteceu em dois momentos. O primeiro momento ocorreu na sala de vídeo com a exibição do filme "As Tartarugas Ninja - Fora das sombras" com a duração de dois tempos de aula. Antes de o filme ser apresentado aos alunos, foi-lhes explicado que deveriam prestar bastante atenção a toda a história, devendo anotar no caderno fatos e nomes para serem citados no resumo que seria feito sobre o filme com o intuito de publicá-lo em um blog da turma.

Durante a exibição do filme, foi servido para os alunos pipoca com refrigerante. Estes demonstraram interesse no enredo do filme, tendo-se envolvido com a atividade, interagindo de forma respeitosa com a professora-pesquisadora e entre si. Ao término do filme, os alunos da turma foram orientados a pensar e preparar anotações individuais sobre o filme para serem trazidas na próxima aula, a fim de compor um resumo.

O segundo momento desta etapa foi a produção de um resumo individual sobre o filme "As Tartarugas Ninja - Fora das sombras", atividade que ocorreu na sala de aula. Primeiramente, houve uma conversa com a turma sobre o filme para relembrar os nomes dos personagens e os fatos principais, sendo anotados no quadro branco. Em seguida, foi entregue uma folha de papel almaço a cada um, para que nela fosse registrado o resumo produzido. Foram dadas todas as orientações para o uso adequado da folha e o cuidado que deveriam ter ao produzir o resumo, por se tratar de um texto que pertence aos eventos de comunicação marcados pelo letramento. Além disso, foi dito que seriam selecionados os sete melhores resumos para serem publicados no blog da turma, devendo ser textos claros, coerentes, com ideias interligadas, aplicação da regra de concordância verbal e obediência aos padrões de ortografia e pontuação. Por consequência, percebeu-se grande empenho por parte de cada aluno em fazer um bom texto. Todos se mostraram concentrados e atentos à produção do resumo, pois a atividade, além de poder ser publicada no blog que seria criado posteriormente para expor os melhores textos da turma, constituiu uma das avaliações do bimestre letivo.

\subsection{Etapa 8: Reescritura do resumo para a versão final}


Esta etapa foi iniciada com a votação do nome do blog em que seriam postadas as produções dos resumos sobre o filme "As Tartarugas Ninja - Fora das sombras”. Sugestões foram dadas pelos alunos e escritas no quadro branco para dar ciência à turma das opções na votação. Pequenos papéis foram entregues a cada um para que escrevessem o seu voto. A opção vencedora foi "Os 701".

Terminada a votação, os alunos receberam de volta os seus resumos produzidos na etapa anterior com as sinalizações da professora, para que fossem reescritos de forma adequada em uma outra folha pautada. Como foi impossibilitado o uso da sala de informática da escola naquele momento, ficou acertado com os alunos que os resumos selecionados seriam digitados e postados posteriormente pela professora-pesquisadora.

A tabela a seguir exibe a computação de todos os dados obtidos a partir dos resumos produzidos:

Tabela 3: Índice de aplicação da regra de CV de $3^{a}$ pessoa do plural em resumos para o blog

\begin{tabular}{|c|c|c|}
\hline CONCORDÂNCIA & NÃO CONCORDÂNCIA & TOTAL \\
\hline 345 & 40 & 385 \\
\hline $90 \%$ & $10 \%$ & $100 \%$ \\
\hline
\end{tabular}

Fonte: Elaboração da autora-pesquisadora, Seropédica, 2016

A tabela mostra a distribuição de 345 dados de concordância verbal de terceira pessoa do plural obtidos a partir de 32 resumos produzidos nesta etapa. Como podemos observar, o índice de aplicação da regra de concordância está próximo à semicategorização proposta por Labov (2003). Esse índice representa o resultado das várias atividades didáticas que foram desenvolvidas com a turma, mostrando que houve avanços no letramento dos alunos no que diz respeito à aplicação da regra, especialmente em eventos de comunicação mediados pela escrita, sobre os quais atua com mais força a ação de agências padronizadoras, como a imprensa (cf. BORTONI-RICARDO, 2004).

Por outro lado, ainda chama a atenção o quantitativo de não aplicação da regra no extremo de [+ letramento] do contínuo. É interessante observar que várias das ocorrências de não aplicação da regra se deram com sujeito pós-verbal e foram constituídas pelo verbo chegar, que costuma apresentar o sujeito à direita, tal qual muitos verbos intransitivos (como faltar e existir, p. ex.), nos quais é comum o cancelamento da concordância devido a essa posposição do sujeito:

(12) (...) e, então chegou as Tartarugas Ninja (...) 
Não obstante os casos de não flexão do verbo para marcar a concordância canônica, percebeu-se, de modo geral, um avanço considerável na concretização da regra de concordância de terceira pessoa do plural no polo de [+ letramento] do contínuo em contextos de verbos foneticamente menos salientes (13), tendo inclusive alcançado contextos de sujeito pós-verbal (14), conforme ilustram os exemplos:

(13) (...) as tartarugas aparecem (...)

(14) (...) fogem também dois prisioneiros.

Em vista disso, podemos dizer que a mediação pedagógica foi muito exitosa no sentido de elevar consideravelmente a aplicação da regra de concordância verbal de terceira pessoa do plural ao longo do contínuo de oralidade-letramento. Os resultados podem ser mais bem visualizados no gráfico a seguir:

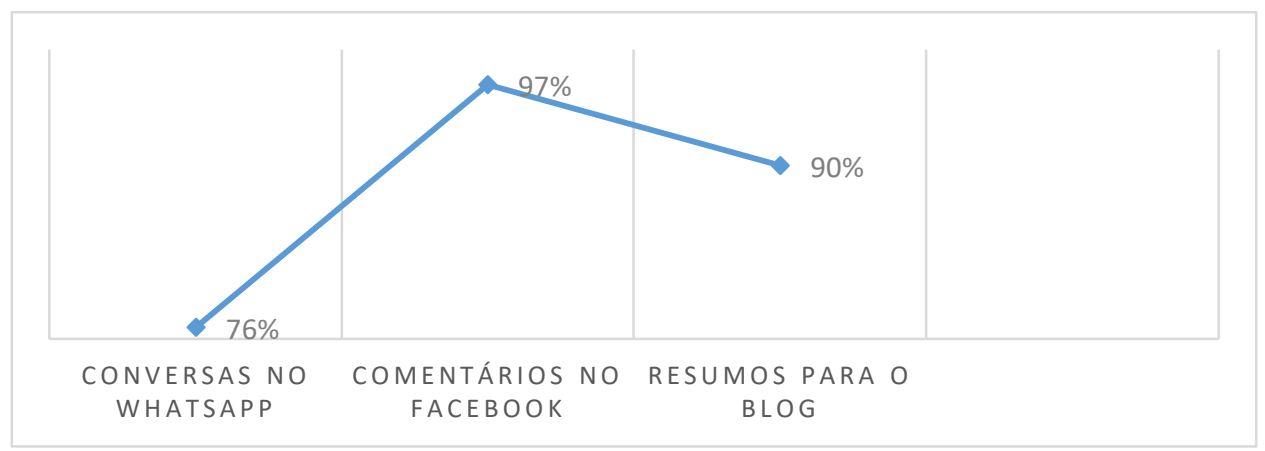

Gráfico 1: Aplicação da regra de concordância de terceira pessoa do plural no contínuo oralidade-letramento (Fonte: Elaboração da autora- pesquisadora, Seropédica, 2016)

Através do gráfico, podemos perceber uma evolução na aplicação da regra de concordância verbal. Mesmo que os comentários opinativos do Facebook fossem desconsiderados em razão dos poucos dados obtidos nessa produção, ainda assim a linha do gráfico seguiria uma trajetória ascendente, uma vez que a última produção da mediação pedagógica, os resumos para o blog, gênero representante do polo [+ letramento], revelou um aumento significativo na aplicação da regra, se comparado às conversas via Whatsapp, representante do polo [+ oralidade]. Dessa forma, por meio das atividades das etapas da mediação pedagógica, os alunos apresentaram avanços em seu processo de letramento, evidenciados pelo aumento do índice de aplicação da regra de concordância de terceira pessoa do plural em textos representativos da cultura letrada, num uso beirando a semicategorização, nos termos de Labov (2003). 
Por fim, foram postados no blog $O s 701^{8}$ sete resumos selecionados por apresentarem clareza e um bom desenvolvimento na descrição do enredo do filme, além da aplicação da regra de concordância verbal, assunto que foi trabalhado no decorrer de toda a mediação pedagógica:

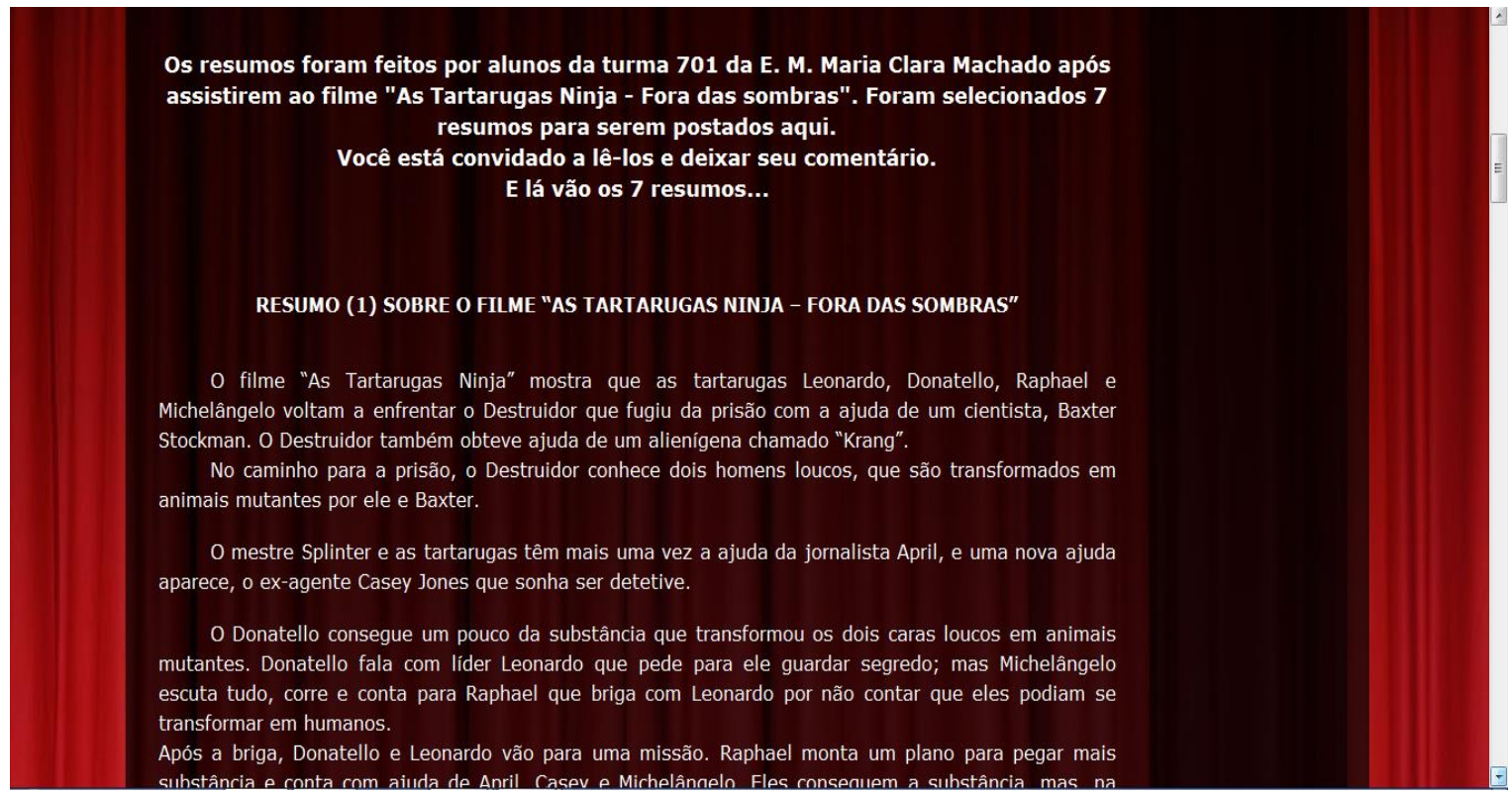

Figura 2-Blog “Os 701” (Fonte: <os701.blogspot.com>

\section{Considerações finais}

Nesta pesquisa-ação propusemos o uso das novas tecnologias a serviço do ensino da concordância verbal de terceira pessoa do plural, por meio de uma mediação pedagógica que lançou mão de diferentes gêneros textuais, distribuídos ao longo de um contínuo oralidadeletramento (cf. BORTONI-RICARDO, 2004), de forma a levar os alunos envolvidos à percepção da concordância verbal como fenômeno variável e à aplicação da regra em contextos socialmente exigidos.

Dado o exposto, consideramos que os objetivos propostos foram satisfatoriamente alcançados, seja o multiletramento digital, seja a ampliação do repertório linguístico dos alunos quanto à concordância verbal de terceira pessoa do plural. Com relação ao primeiro objetivo, percebemos que, durante a aplicação da mediação pedagógica, os alunos manipularam (apesar

\footnotetext{
${ }^{8} \mathrm{O}$ blog da turma foi criado após a conclusão da mediação pedagógica. Disponível em: <os701.blogspot.com>.
} 
de todos os entraves na escola) diferentes plataformas digitais, concorrendo para o seu letramento digital. É verdade que, de modo geral, eles já faziam uso dessas tecnologias (WhatsApp, Facebook), mas até então nunca tinham tido a experiência de associá-las ao processo de aprendizagem, o que certamente deu mais sentido às produções textuais realizadas com esses suportes digitais.

No que diz respeito ao segundo objetivo, logo na primeira etapa da mediação pedagógica, ao analisar a primeira produção textual, verificamos um índice não desprezível de não aplicação da regra de concordância verbal de terceira pessoa do plural, mesmo os alunos pertencendo à população de área urbana, teoricamente com mais contato com agências padronizadoras, como a grande mídia. Dessa maneira, através das produções textuais realizadas no decorrer da mediação pedagógica, iniciadas pelas conversas via WhatsApp, passando pelos comentários opinativos no Facebook e culminando com os resumos escritos para o blog, percebemos que os alunos aumentaram a frequência da regra típica das normas urbanas de prestígio em direção à semicategorização.

A cada produção, os alunos foram levados a perceber a variação linguística existente e a reconhecer os diferentes tipos de eventos de comunicação, desde os mais característicos da oralidade até aqueles próprios da cultura de letramento. Por outro lado, no extremo de [+ letramento] do contínuo ainda foram encontrados dados de não aplicação da regra de concordância verbal de terceira pessoa do plural, o que pôde ser perfeitamente explicado por contextos estruturais que interferem na aplicação da regra, como o fator saliência fônica, conforme descrevem diferentes trabalhos acadêmicos. O estudo de Scherre e Naro (1997), por exemplo, já mostrava que as formas verbais menos salientes desfavorecem a aplicação da regra de concordância. Do mesmo modo, a posposição do sujeito também é outro contexto que leva a menores cuidados com a concordância verbal, como mostra Vieira (2014). Por conseguinte, os resultados obtidos no polo de [+ letramento] do contínuo por este trabalho estão próximos dos descritos por outras pesquisas sociolinguísticas sobre a fala de indivíduos cultos, como Graciosa (1991) e Monguilhott (2001), o que ratifica ser a escolarização um fator relevante para a concretização da regra de concordância verbal de terceira pessoa do plural.

Não obstante os resultados satisfatórios obtidos, percebemos que é necessário dar continuidade ao trabalho de letramento dos alunos, visto que é um processo que não se esgota num único ano de escolaridade, mas se constrói ao longo da formação escolar. Assim, para ser bem sucedida nessa empreitada, a escola precisa inserir a variação linguística na abordagem dos fatos da língua, de maneira a romper sempre mais com a tradicional ideologia do "certo" e 
do "errado" quanto aos fenômenos variáveis, para que supere o preconceito linguístico ainda presente na sociedade e amplie o conhecimento dos alunos acerca da pluralidade de normas existentes na língua portuguesa.

\section{Referências}

BORTONI-RICARDO, Stella Maris. Educação em língua materna: a sociolinguística na sala de aula. São Paulo: Parábola Editorial, 2004.

BRASIL. Guia de livros didáticos: PNLD 2011: Língua Portuguesa. Brasília: MEC/SEB, 2010.

DUARTE, Maria Eugenia Lammoglia; SERRA, Carolina Ribeiro. Gramática(s), ensino de português e "adequação linguística". Matraga, v. 22, n. 36, p. 31-55, jan./jun., 2015. Disponível em: <http://dx.doi.org/10.12957/matraga. 2015.17046>. Acesso em: 06 dez. 2016.

FARACO, Carlos Alberto. Norma culta brasileira: desatando alguns nós. São Paulo, Parábola Editorial, 2008.

GRACIOSA, Diva Maria Dias. Concordância verbal na fala culta carioca. Dissertação (Mestrado em Língua Portuguesa). Rio de Janeiro: Faculdade de Letras, UFRJ, 1991.

LABOV, William. Some sociolinguistic principles. In: PAULSTON, C. B.; TUCKER, G. R. (org.). Sociolinguistics: the essential readings. Oxford: Blackwell, 2003. p. 234-250.

MONGUILHOTT, Isabel de Oliveira e Silva. Um estudo da concordância verbal de terceira pessoa em Florianópolis. Dissertação (Mestrado em Linguística). Florianópolis: Faculdade de Letras, UFSC, 2001.

OLIVEIRA, Marian dos Santos. Concordância verbal de terceira pessoa do plural em Vitória da Conquista: variação estável ou mudança em progresso? Dissertação (Mestrado em Letras e Linguística). Salvador: Faculdade de Letras, UFBA, 2005.

RIBEIRO, Ana Elisa. Novas tecnologias para ler e escrever-algumas ideias sobre ambientes e ferramentas digitais na sala de aula. Belo Horizonte: RHJ, 2012.

Textos multimodais: leitura e produção. São Paulo: Parábola Editorial, 2016.

SCHERRE, Maria Marta Pereira; NARO, Anthony Julius. A concordância de número no Português do Brasil: um caso de variação inerente. In: HORA, Demerval (org.). Diversidade linguística no Brasil. João Pessoa: Ideia, 1997. p. 93-115.

THIOLLENT, Michel. Metodologia da Pesquisa-ação. São Paulo: Cortez, 2011.

VIEIRA, Silvia Rodrigues. Concordância verbal. In: VIEIRA, Silvia Rodrigues; BRANDÃO, Silvia Figueiredo (org.). Ensino de gramática: descrição e uso. 2. Ed, $2^{a}$ reimpressão. São Paulo: Contexto, 2014. p. 85-102 
; FREIRE, Gilson Costa. Variação morfossintática e ensino de português. In: MARTINS, Marco Antonio et al (org.). Ensino de português e Sociolinguística. São Paulo: Contexto, 2014. p. 81-114.

Enviado em 30 de maio de 2018. Aceito em 18 de setembro de 2018. 